\title{
Transcriptomic Profiles of Brain Provide Insights into Molecular Mechanism of Feed Conversion Efficiency in Crucian Carp (Carassius auratus)
}

\author{
Meixia Pang ${ }^{1,2}$, Weiwei Luo ${ }^{1}$, Beide Fu ${ }^{1}{ }^{\mathbb{D}}$, Xiaomu Yu ${ }^{1}$, Ying Zhou ${ }^{1,2}$ and Jingou Tong ${ }^{1, *}$ \\ 1 State Key Laboratory of Freshwater Ecology and Biotechnology, Institute of Hydrobiology, \\ The Chinese Academy of Sciences, Wuhan 430072, China; pang1mei2xia3@163.com (M.P.); \\ weiweiluo66@163.com (W.L.); fubeide@163.com (B.F.); xmyu@ihb.ac.cn (X.Y.); Memoria_Y@163.com (Y.Z.) \\ 2 University of Chinese Academy of Sciences, Beijing 100049, China \\ * Correspondence: jgtong@ihb.ac.cn; Tel.: +86-27-6878-0751; Fax: +86-27-6878-0123
}

Received: 19 January 2018; Accepted: 12 March 2018; Published: 14 March 2018

\begin{abstract}
Feed efficiency is an economically crucial trait for cultured animals, however, progress has been scarcely made in the genetic analyses of feed conversion efficiency (FCE) in fish because of the difficulties in measurement of trait phenotypes. In the present investigation, we present the first application of RNA sequencing (RNA-Seq) combined with differentially expressed genes (DEGs) analysis for identification of functional determinants related to FCE at the gene level in an aquaculture fish, crucian carp (Carassius auratus). Brain tissues of six crucian carp with extreme FCE performances were subjected to transcriptome analysis. A total of 544,612 unigenes with a mean size of $644.38 \mathrm{bp}$ were obtained from Low- and High-FCE groups, and 246 DEGs that may be involved in FCE traits were identified in these two groups. qPCR confirmed that genes previously identified as up- or down-regulated by RNA-Seq were effectively up- or down-regulated under the studied conditions. Thirteen key genes, whose functions are associated with metabolism (Dgkk, Mgst3 and Guk1b), signal transduction (Vdnccsa1b, Tgf $\alpha, N r 4 a 1$ and Tacr2) and growth (Endog, Crebrtc2, Myh7, Myh1, Myh14 and Igfbp7) were identified according to GO (Gene Ontology) and KEGG (Kyoto Encyclopedia of Genes and Genomes) annotations. Our novel findings provide useful pathway information and candidate genes for future studies of genetic mechanisms underlying FCE in crucian carp.
\end{abstract}

Keywords: crucian carp (Carassius auratus); feed conversion efficiency; brain; differentially expressed genes; RNA-Seq

\section{Introduction}

Aquaculture products are among the most important sources of nutrition for people around the world [1]. Fish is a key source of protein, essential amino-acids and minerals, especially in low-income, food-deficient countries [2-4]. In the past decades, yield-related traits in fish have been extensively studied by researchers to meet the ever-increasing global demand and increase financial returns $[5,6]$. Since feed cost comprises about $65-75 \%$ of the total production cost in most aquaculture species [7], the increasing production demand with huge input cost kept up pressures on us to investigate how to improve feed efficiency. In this sense, breeding fish with high feed efficiency would mean big savings and enhance the profitability of producers.

Feed efficiency was usually measured as feed conversion ratio (FCR), which is the ratio of feed intake to body weight gain [8]. To date, some DNA variants playing roles in feed efficiency have been proposed in livestock [8-11] and poultry industry [12-15] using quantitative trait loci (QTL) mapping and association studies. Those identified candidate genes pertain to numerous biological processes $[10,16]$, suggesting that biological strategies involving feed efficiency are diverse. 
RNA sequencing (RNA-Seq) technology combined with the analysis of differentially expressed genes (DEGs) are reliable and precise ways to provide useful information for molecular mechanism of complex characters [17]. Moreover, RNA-Seq has attracted considerable interests and received great success concerning many economic traits in some other cultured species [18-20]. An increasing number of studies have addressed the transcriptomic profiles of tissues and organs to examine the variety of functional pathways underlying inter-individual difference in feed efficiency [21-25], which focused on target organs such as intestine [21] and liver [22,23], but no similar analysis has been done in neural organs. Moreover, genetic studies on feed efficiency have been scarcely reported in aquaculture species [26,27].

Crucian carp (Carassius auratus) is an economically important aquaculture species worldwide [28]. For this fish, progress on improving feed efficiency has mainly focused on changes in external conditions $[29,30]$. To date, the only one study about OTL mapping for feed conversion efficiency (FCE, the inverse of FCR) was reported by our laboratory in crucian carp [31]. In a previous study, seven candidate genes associating with FCE and its relevant traits were identified, such as mapk11, cse1l, fam126b, myh14, rgs $9 b p$, cldn10a and cldn10b, involved in several biological functions. So far, few transcriptome analyses have been conducted in crucian carp. Liao, et al. conducted differential gene expression analyses among four tissues [32], and $\mathrm{Li}$, et al. performed RNA-Seq to determine functional differences and DEGs between gibel carps and crucian carp using ten tissues of each species [33]. No transcriptome analysis has been conducted for FCE in this fish. Here, we used high-throughput sequencing of mRNAs from brain tissues of six crucian carps with extreme phenotypes of FCE. We aimed to find novel genes and biological pathways that may be related to feed efficiency of crucian carp, which would provide a better understanding of genetic mechanisms underlying FCE in fish.

\section{Results}

\subsection{Transcriptome Sequencing and Statistics of Unigenes}

After quality filtering, the RNA-Seq of six brain samples yielded around 52.59 million high-quality sequence data. The Q30 values of each sample were up to $93.20 \%$, and GC-content of each sample ranged from $45.33 \%$ to $49.44 \%$ (Table 1). The clean reads obtained from the six transcriptome libraries were assembled to full-length transcripts, and a total of 544,612 unigenes were achieved after elimination of redundant transcripts. Summary data of the assembled transcripts and unigenes are given in Table 2, and the number of unigenes per size that normally decreases continuously is shown in Table 2 and Figure S1.

Table 1. Overview of the sequencing reads.

\begin{tabular}{ccccccc}
\hline Samples & H1 & H2 & H3 & L1 & L2 & L3 \\
\hline Raw reads & $51,467,792$ & $50,558,463$ & $54,265,382$ & $53,444,150$ & $56,248,579$ & $55,784,163$ \\
Clean reads & $50,530,680$ & $49,250,952$ & $53,769,034$ & $52,491,591$ & $55,011,113$ & $54,460,392$ \\
Q30 & $93.20 \%$ & $93.76 \%$ & $93.65 \%$ & $93.37 \%$ & $93.84 \%$ & $93.79 \%$ \\
GC-content & $48.04 \%$ & $46.68 \%$ & $48.84 \%$ & $49.44 \%$ & $47.37 \%$ & $45.33 \%$ \\
Mapped reads & $29,173,543$ & $31,871,361$ & $31,789,018$ & $30,732,102$ & $33,802,037$ & $35,592,419$ \\
Mapped ratio & $57.73 \%$ & $64.71 \%$ & $59.12 \%$ & $58.55 \%$ & $61.45 \%$ & $65.35 \%$ \\
\hline
\end{tabular}


Table 2. Summary of the assembled transcripts and unigenes.

\begin{tabular}{ccc}
\hline Length Range & Transcript & Unigene \\
\hline $200-300$ & $283,078(18.32 \%)$ & $209,625(38.49 \%)$ \\
$300-500$ & $264,160(17.09 \%)$ & $151,108(27.75 \%)$ \\
$500-1000$ & $316,468(20.48 \%)$ & $102,120(18.75 \%)$ \\
$1000-2000$ & $360,982(23.36 \%)$ & $50,873(9.34 \%)$ \\
$2000+$ & $320,919(20.76 \%)$ & $30,886(5.67 \%)$ \\
Total Number & $1,545,607$ & 544,612 \\
Total Length & $1,940,292,597$ & $350,936,744$ \\
N50 Length & 2091 & 965 \\
Mean Length & $1,255.36$ & 644.38 \\
\hline
\end{tabular}

\subsection{Functional Annotation and Classification of Unigenes}

All the unigene sequences were subjected to a search against Nr [34], Swissprot [35], COG [36] and KEGG [37] databases. Among these unigenes, totally 76,060 unigenes $(13.97 \%$ of all the 544,612 unigene sequences) were annotated in four public databases, including 68,168 (12.52\%) in Nr, 27,535 (5.06\%) in Swissprot, $12,550(2.30 \%)$ in COG and 29,390 (5.40\%) in KEGG, respectively.

GO assignment was performed to classify functions of the predicted crucian carp genes. Based on sequence homology, a total of 27,785 unigenes were annotated to 62 terms of GO classification, which were classified into three major functional categories: biological process (21,797 unigenes, $78.45 \%)$, cellular component (16,807 unigenes, $60.49 \%)$ and molecular function $(22,584$ unigenes, $81.28 \%$ ) (Figure 1).

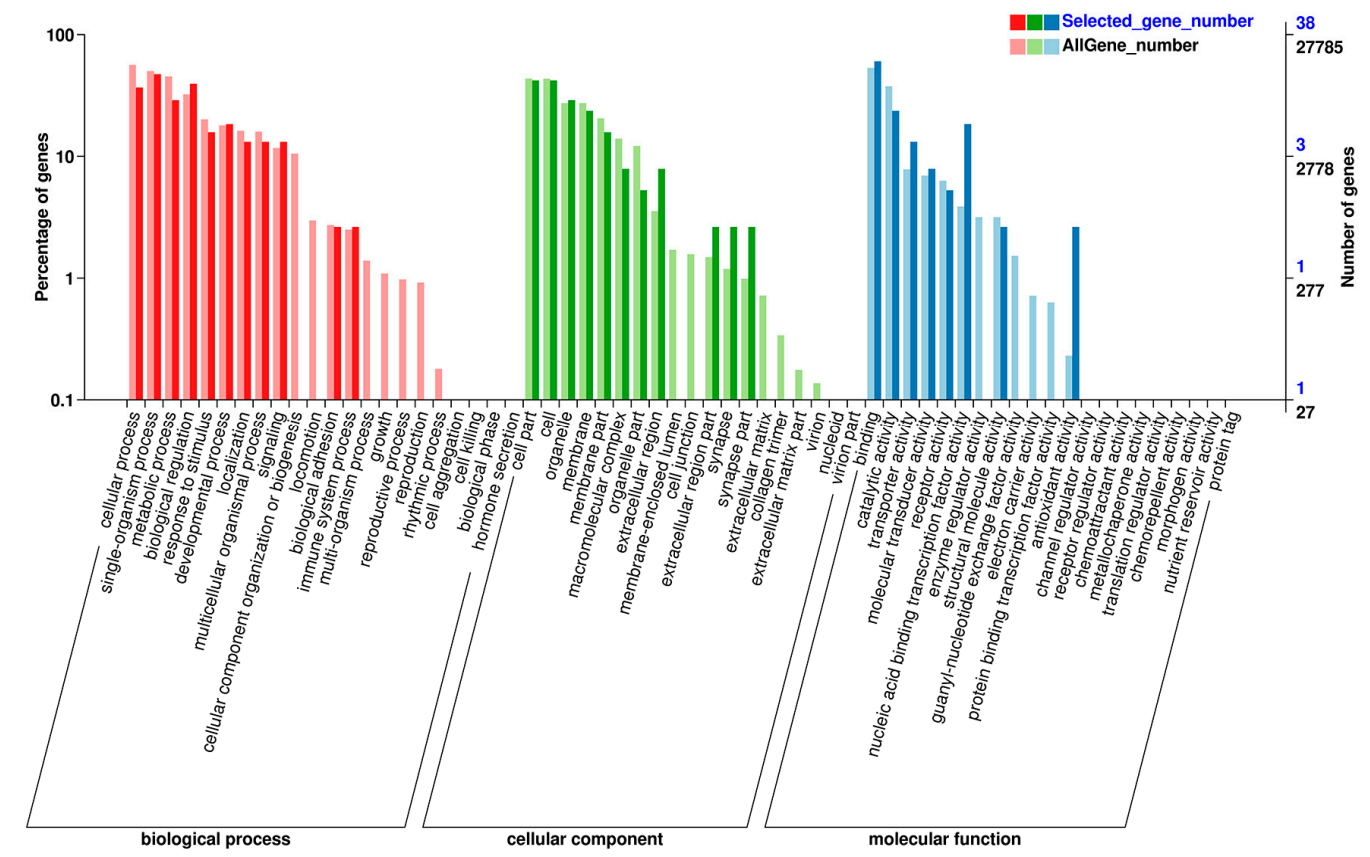

Figure 1. GO classifications of all unigenes and DEGs associating with feed conversion efficiency from brain samples of crucian carp.

\subsection{Identification of Differentially Expressed Genes (DEGs)}

Overall, $61.15 \% \pm 3.26 \%$ of clean reads per sample were mapped back to the assembled transcripts (Table 1); 246 DEGs (Table S1) were identified in the comparison of Low_vs_High FCE groups, with 132 up-regulated and 114 down-regulated genes in the High group, respectively. Among these DEGs, a total of 113 genes were annotated in at least one of the four ( $\mathrm{Nr}$, Swissprot, COG and KEGG) databases. 


\subsection{Enrichment for Functional Analysis of DEGs}

The results of COG enrichment analysis for the annotated DEGs are shown in Figure 2. Replication, recombination and repair $(\mathrm{L}, 22-51.16 \%$ ) annotated the most DEGs in the comparison of Low_vs_High FCE groups, followed by transcription (K, 4-9.3\%) and signal transduction mechanisms ( $\mathrm{T}, 4-9.3 \%)$.

A total of 38 DEGs were annotated to 30 terms of GO classification (Figure 1). Under the biological process category, cellular process (14 DEGs, 36.84\%), single-organism process (18 DEGs, 47.37\%), biological regulation (15 DEGs, 39.47\%) and metabolic process (11 DEGs, 28.95\%) have the most abundant GO function items. In the cellular component category, a significant percentage of genes were clustered into cell (16 DEGs, $42.11 \%$ ), cell part (16 DEGs, 42.11\%), organelle (11 DEGs, $28.95 \%$ ) and membrane (nine DEGs, $23.68 \%$ ). Within the molecular function category, most genes were assigned to binding (23 DEGs, 60.53\%) and catalytic activity (nine DEGs, $23.68 \%$ ).

Pathway analyses were performed using mapped DEGs to other species' orthologues to get more insights into the effects of FCE on metabolisms in the crucian carp. 20 statistically enriched pathways $(p<0.05)$ were revealed by KEGG pathway analysis, including four in cellular processes, seven in environmental information processing, three in genetic information processing, six in metabolism, and two in organismal systems categories, respectively (Table 3).

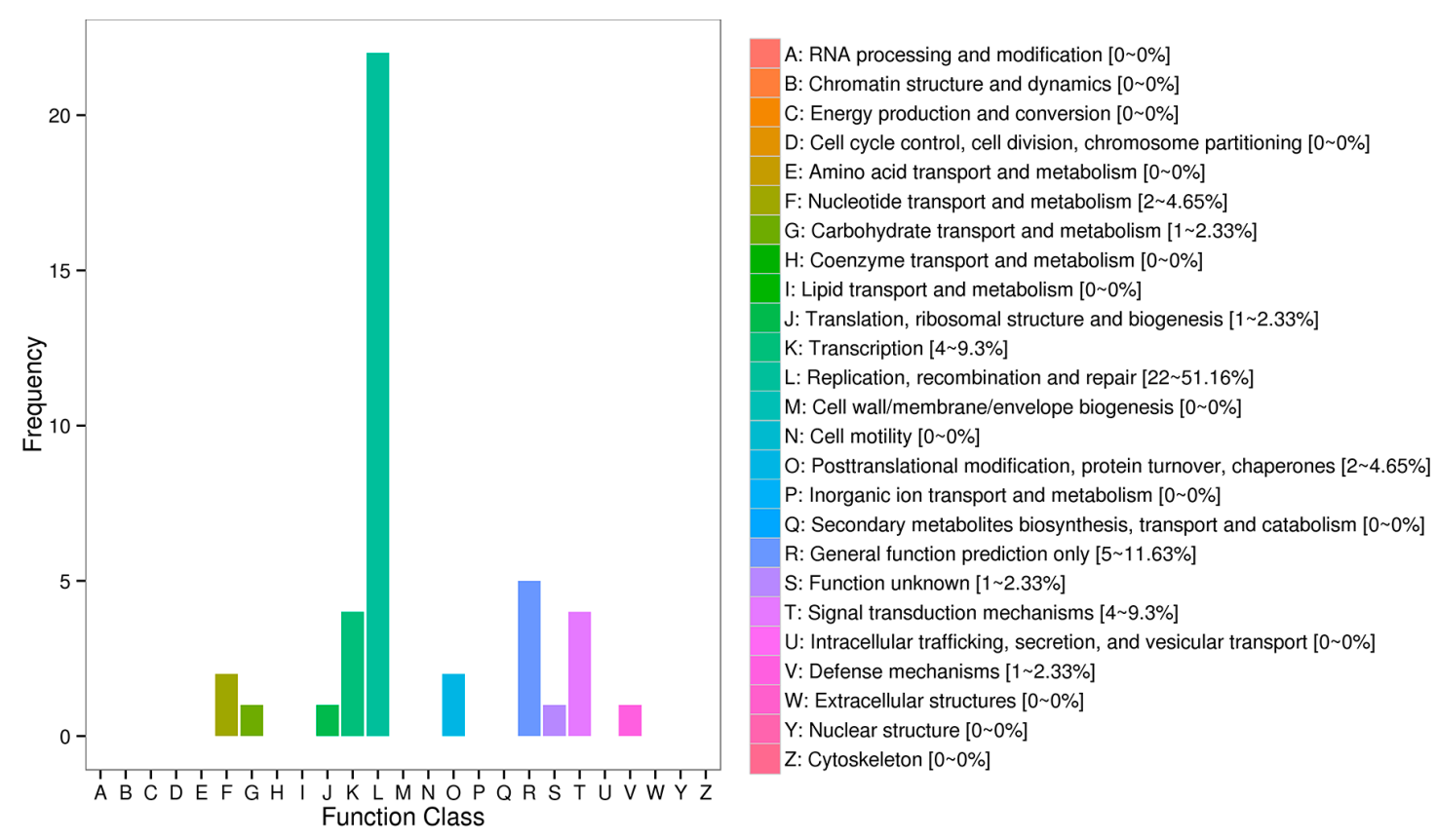

Figure 2. COG classifications of DEGs associating with feed conversion efficiency from brain samples of crucian carp. 
Table 3. Pathways associating with feed conversion efficiency of crucian carp.

\begin{tabular}{|c|c|c|c|c|}
\hline \multicolumn{2}{|c|}{ KEGG Category } & \multirow{3}{*}{$\begin{array}{c}\text { Pathway Name } \\
\text { Apoptosis } \\
\text { Cell cycle }\end{array}$} & \multirow{2}{*}{$\begin{array}{c}\text { Pathway ID } \\
\text { ko04210 }\end{array}$} & \multirow{2}{*}{$\begin{array}{l}\text { DEGs } \\
\text { Endog }\end{array}$} \\
\hline Cellular Processes & Cell growth and death & & & \\
\hline & 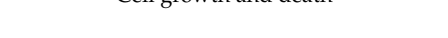 & & ko04110 & Crebrtc2 \\
\hline & Cell motility & Regulation of actin cytoskeleton & ko04810 & Nckap1 \\
\hline & Cellular community & Tight junction & ko04530 & Myh7, Myh \\
\hline \multirow{7}{*}{$\begin{array}{l}\text { Environmental Information } \\
\text { Processing }\end{array}$} & Membrane transport & $\mathrm{ABC}$ transporters & ko02010 & Abcb11 \\
\hline & Signal transduction & Calcium signaling pathway & ko04020 & Vdnccsa1b, Tacr2, Htr7 \\
\hline & & ErbB signaling pathway & ko04012 & T\&fa \\
\hline & & MAPK signaling pathway & ko04010 & Vdnccsa1b, Nr4a1 \\
\hline & & Phosphatidylinositol signaling system & ko04070 & $D g k k$ \\
\hline & Signaling molecules and interaction & Cytokine-cytokine receptor interaction & ko04060 & Xcr1 \\
\hline & & Neuroactive ligand-receptor interaction & ko04080 & Tacr2, Htr7 \\
\hline \multirow[t]{3}{*}{ Genetic Information Processing } & Replication and repair & Base excision repair & ko03410 & Cdcpсec1 \\
\hline & Transcription & Basal transcription factors & ko03022 & Qtf $2 f 2 b$ \\
\hline & Translation & RNA transport & ko03013 & Tef1 \\
\hline \multirow[t]{6}{*}{ Metabolism } & Lipid metabolism & & ko00561 & Dgkk \\
\hline & Бір & Glycerophospholipid metabolism & ko00564 & $D g k k$ \\
\hline & Metabolism of other amino acids & Glutathione metabolism & ko00480 & Mgst 3 \\
\hline & Nucleotide metabolism & Purine metabolism & ko00230 & Guk1b \\
\hline & Xenobiotics biodegradation and metabolism & Drug metabolism — cytochrome P450 & ko00982 & Mgst 3 \\
\hline & & Metabolism of xenobiotics by cytochrome P450 & ko00980 & Mgst 3 \\
\hline \multirow{2}{*}{ Organismal Systems } & Circulatory system & Adrenergic signaling in cardiomyocytes & ko04261 & Myht \\
\hline & & Cardiac muscle contraction & ko04260 & Myht \\
\hline
\end{tabular}




\subsection{Critical DEGs Involved in Feed Conversion Efficiency of Crucian Carp}

Among all DEGs identified by RNA-Seq analysis, most of the annotated DEGs were classified into molecular function associating with ATP/GTP binding (GO:0005524/GO:0005525), ATP catabolic process (GO:0006200), signal transduction (GO:0007165) and metabolic process (GO:0008152), suggesting that FCE in crucian carp was mainly associated by such kind of pathways as energy metabolism and signal transduction. KEGG analysis also classified DEGs mainly into metabolism and signal transduction, suggesting that these genes may be considered as key candidate genes associating with FCE. Three candidate genes were enriched in metabolism pathways, including $D g k k$ (Diacylglycerol kinase kappa), Mgst3 (Microsomal glutathione S-transferase 3) and Guk1b (Guanylate kinase $1 b)$. Whereas five genes were classified into signal transduction pathways, such as $V d n c c s a 1 b$ (Voltage-dependent N-type calcium channel subunit alpha-1B-like) and Tacr2 (Tachykinin receptor 2) in calcium signaling pathway, $T g f \alpha$ (Transforming growth factor alpha) in ErbB signaling pathway, $V d n c c s a 1 b$ and Nr4a1 (Nuclear receptor subfamily 4 group A member 1) in MAPK signaling pathway, and $D g k k$ in phosphatidylinositol signaling system. Attentions to the DEGs with functions involved in growth, such as Endog (Endonuclease G), Crebrtc2 (cAMP-response element binding protein CREB-regulated transcription coactivator 2-like), Myh7 (myosin heavy chain 7), Myh1 (Myosin heavy chain 1), Myh14 (Myosin heavy chain 14) and Igfbp7 (Insulin-like growth factor-binding protein 7), should be also paid because this trait is highly correlated with FCE.

\subsection{Validation of RNA-Seq Results by Quantitative Real-Time RT-PCR ( $q R T-P C R$ )}

qRT-PCR was performed for nine randomly selected DEGs to validate the RNA-seq results obtained in the current study. These tested DEGs included c353179.graph_c0 (Myh7), c370016.graph_c0 (Granulin), c381143.graph_c0 (Cdh26), c359802.graph_c0 (Mgst3), c356058.graph_c0 (unnamed), c282511.graph_c0 (unnamed), c417566.graph_c1 (Dgkk), c385041.graph_c0 (Evx2) and c406285.graph_c0 (Guk1b). The fold changes detected by qRT-PCR were comparable with the RNA-Seq expression profiles. In general, the expression patterns obtained by qRT-PCR were similar to those revealed by RNA-seq (Figure 3), confirming the data reliability of up or down- regulated DEGs obtained by RNA-seq.

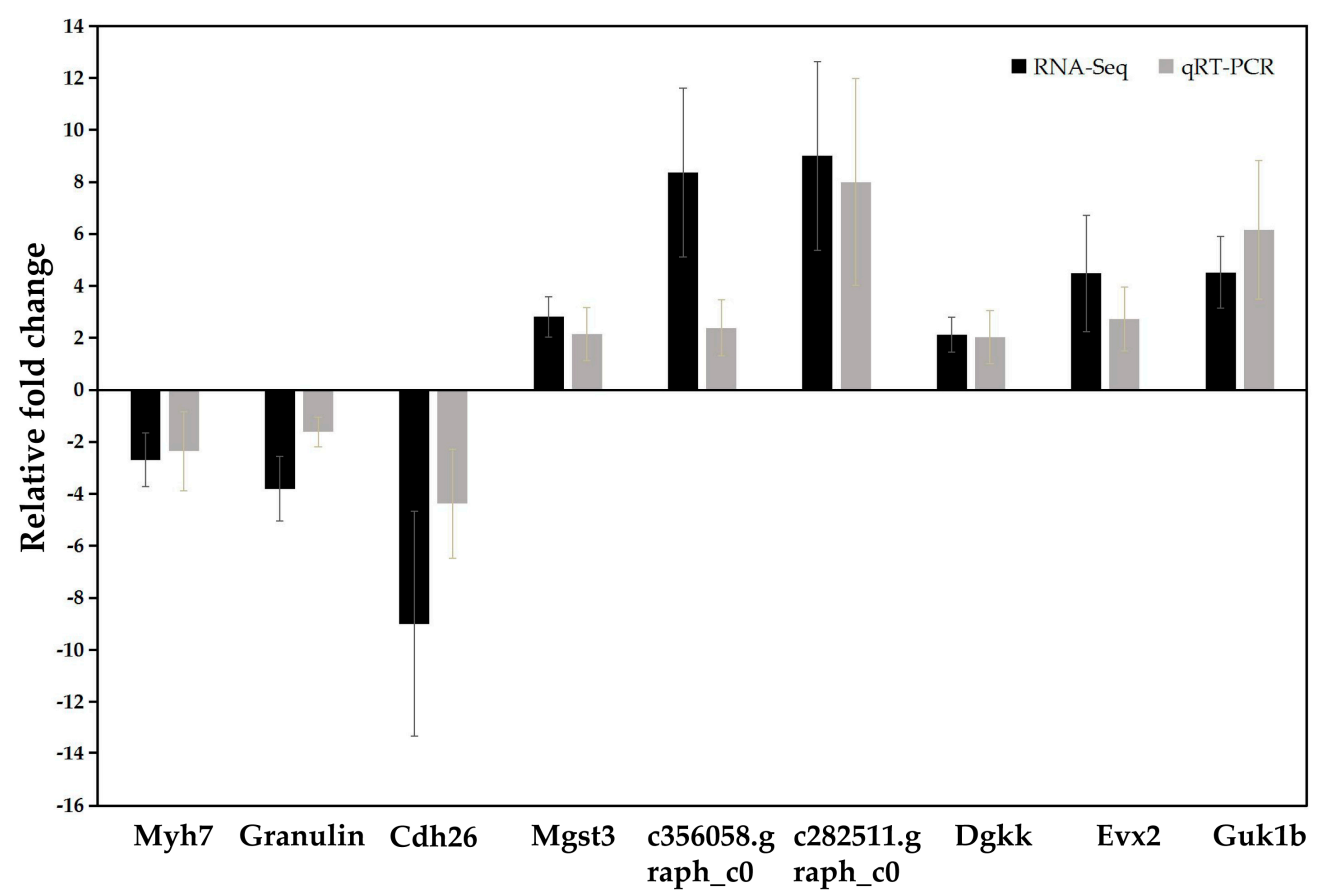

Figure 3. Illustration of qRT-PCR confirmation results for 9 randomly selected DEGs. 


\section{Discussion}

Efficient production of animals plays an important role in livestock [38], poultry [21] and aquaculture [39] industries. This implies the reduction of input costs and the increase of financial returns for producers. In almost all animal production systems, feed cost is the major component (30-70\%) of the total costs [40]. Improvement in feed efficiency means reducing the amount of feed resources needed to produce meat and contributing to environmental sustainability [41]. Moreover, it has been reported that feed efficiency is involved in numerous biological processes and functional pathways [10,16], and this trait can be improved by breeding and feeding strategies [24]. Eight QTL associated with FCE, an assessment criterion for feed efficiency, were mapped to four linkage groups, explaining $15.2-20.9 \%$ of the phenotypic variations, and seven candidate genes related to FCE and its relevant traits involved in several biological processes were identified in crucian carp in a previous study [34]. In this study, we performed a pioneering and comparative transcriptome analysis based on brain tissues of six crucian carp with extreme FCE phenotypes to help us to understand the molecular mechanisms of FCE. This study is, to the best of our knowledge, the first report of identification of functional determinants involved in FCE at the gene level by transcriptome analysis in fish.

The current RNA-Seq work provided high-quality sequences, and the proportions of mapped reads per sample ranged from $57.73 \%$ to $65.35 \%$ (Table 1), which ensured the accuracy and reliability of subsequent differential expression analysis. Feed efficiency could be influenced by feed intake to a large content [42], and the brain is a major part of the neural organs that regulates feed intake activity and metabolism in earlier stage of the whole physiological processes in fish. Therefore, fish with significantly different FCE traits may be reflected by RNA profiles in brain. In this study, a total of 544,612 unigenes with a mean size of 644.38 bp (Table 2) were obtained from two groups with extreme FCE performance (namely Low and High groups) of brain tissues in crucian carp, and 246 DEGs (Table S1) that may be involved in FCE were identified. Zhao, et al. identified 300 significantly differentially expressed transcripts in liver of pig [22], while $\mathrm{Yi}$, et al. found 41 promising candidate genes in duodenal of chicken [21]. Compared to these similar reports conducted in other animals, moderate numbers of DEGs were found from brains of crucian carp in this investigation.

According to the results of our previous work conducted using QTL mapping methods [31], identified candidate genes associating with FCE could be classified into three categories: genes encoding GTPase/ATP binding protein, tight junction protein and signal transduction regulator. Moreover, the significantly enriched GO terms of all the predicted crucian carp DEGs in the brain identified in this study were mainly associated with molecular function related to ATP/GTP binding (GO:0005524/GO:0005525), ATP catabolic process (GO:0006200), signal transduction (GO:0007165) and metabolic process (GO:0008152), supporting the hypothesis that FCE of crucian carp are mainly regulated by such pathways as energy metabolism and signal transduction. It has also been reported that energy and vitamin A metabolism pathways in the liver were important for feed efficiency in pigs [22]. Due to relatively a small number of DEGs being annotated in curcian carp, only three candidate genes ( $D g k k, M g s t 3$ and Guk1b) were enriched in KEGG pathways of metabolism, including lipid metabolism, glutathione metabolism, purine metabolism, xenobiotics biodegradation and metabolism that are involved in immune system (Table 3). Dgkk is a member of $D g k$ (Diacylglycerol kinase) family, which plays an important role in modulating the balance between diacylglycerol and phosphatidic acid [43]. Mgst3 is related to defense mechanisms associated with oxidative stress by utilizing reduced glutathione [44]. For Guk1b, it can affect the metabolism of GTP [45]. A lipid metabolism pathway was the mostly reported pathway that may associate with feed efficiency in other animals $[21,24,25,46]$, suggesting that $D g k k$ may be considered as an especially critical candidate gene affecting FCE in crucian carp. Moreover, genes related to the immune system were also identified in the transcriptome analyses of feed efficiency in beef [23] and pigs [24].

Another large class of concerned pathways involved in FCE is signal transduction. In this study, calcium signaling pathway (Vdnccsa1b and Tacr 2$)$, ErbB signaling pathway $(T g f \alpha)$, MAPK signaling pathway (Vdnccsa1b and Nr4a1) and phosphatidylinositol signaling system (Dgkk) were found (Table 3) 
from brain tissues of crucian carp. Among these pathways, ErbB signaling could regulate cell proliferation, differentiation and apoptosis through Akt, MAPK and other signaling pathways. Genes enriched in MAPK signaling pathway related to feed efficiency were generally reported by previous researchers [46,47], such as Fgf (Fibroblast growth factor), Tgfbr (Transforming growth factor beta receptor), Pkc (Protein kinase C) and Hsp72 (72-kd heat shock protein) in beef cattle. Additionally, similar candidate genes associating with FCE have also been found in other animals, which suggested that techniques and strategies employed in these studies were reliable and feasible. $T g f \alpha$ is an up-regulating gene in High group of crucian carp involved in ErbB signaling pathway in this study, while Tgfbr is also associated with feed efficiency in chicken [48] and common carp [26]. Igf1 (Insulin-like growth factor 1) is an important regulator of muscle growth and energy metabolism [49,50] that was identified as a candidate gene involved in feed efficiency in chicken [51] and common carp [26]. Igfbp3 (Insulin-like growth factor-binding protein 3) and Igfbp7 are Igf binding proteins in circulation and played important roles in modulating I $f$ bioavailability and half-life, which were respectively found in beef [23] and crucian carp. Both Myh7 and Myh1 were digged out in this report that may be involved in regulating muscle growth, and $M y h 7$ has also been found to be differentially expressed between low- and high-FCR groups in pigs [22]. Moreover, Myh14, another gene from Myh superfamily that plays an important role in fish muscle formation [52], has been identified in our previous work conducted using QTL mapping method in crucian carp [31]. The consistent result obtained in both studies suggesting that Myh14 may be also considered as an especially critical candidate gene affecting FCE in crucian carp.

The reliability of RNA-Seq analysis was confirmed by the concordance between the computational and experimental results by employing nine randomly selected DEGs for qRT-PCR assays in this study, which was similar to some previous studies in animals [53-55]. Since there is no reference genome for Carassius auratus, most unigenes were not well annotated in all annotation databases. At present, a well-assembled genome of crucian carp is needed, and it may help to find more key candidate genes potentially related to feed efficiency. Our results would provide useful information for a physiological basis to develop improved feed formulas and/or feeding conversions. Furthermore, these novel findings would be useful for such future studies as association analysis and functional verification between candidate genes and FCE traits, thereafter providing proper markers for marker-assisted selection for potential improvement of feed efficiency in crucian carp.

\section{Materials and Methods}

\subsection{Sample Collection and RNA Preparation}

A reference family consisting of 120 diploid crucian carp fingerlings, generated by parents from Zhangdu Lake, Yangtze River (Wuhan, China) using artificial crossing in April, 2015, was used in this study. At 82 days post hatch (dph), these reference fish (mean body weight of $0.87 \pm 0.39 \mathrm{~g}$ ) were individually reared in the same environment with pallet feed in a series of re-circulating aquarium tanks in order to achieve accurate feed consumption. Such detailed conditions of the aquarium tanks as water temperature $\left(27-28^{\circ} \mathrm{C}\right)$, dissolved oxygen $(7-8 \mathrm{mg} / \mathrm{L})$ and water flow rate $\left(1 \mathrm{~ms}^{-1}\right)$, were regularly maintained throughout the feeding test for two months. During the experimental period, all test fish were fed three times (10:00 am, 15:00 pm and 20:00 pm) a day by the same fish-feeder, and the fish-feeder stopped feeding when the fish satiated each meal. Faeces generated by experimental fish in each tank were siphoned out once a day and a complete water change was made once a week. The individual body weight $(\mathrm{BW})$ was recorded at the start (initial BW, $\mathrm{BW}_{\mathrm{I}}$ ) and the end (final $\mathrm{BW}$, $\mathrm{BW}_{\mathrm{F}}$ ) of the experiment to calculate $\mathrm{BW}$ gain. The feed conversion efficiency (FCE) was estimated with the model as follows:

$$
\mathrm{FCE}=\left(\mathrm{BW}_{\mathrm{F}}-\mathrm{BW}_{\mathrm{I}}\right) / \mathrm{FI}
$$

Here $\mathrm{FCE}=$ feed conversion efficiency, $\mathrm{BW}_{\mathrm{F}}=$ final body weight, $\mathrm{BW}_{\mathrm{I}}=$ initial body weight, $\mathrm{FI}=$ total feed intake of each individual, which was recorded as the difference between the final and 
the beginning weight of diet used during the test. The detailed information of this feeding test was described in previous study [31].

Fish with extreme FCE phenotypes were used for RNA extraction. At the end of the whole experimental period, we selected six fish consisting of two groups (three biological replicates per group) to represent two divergent FCE performances (Low group: L1-L3 and High group: H1-H3). Table 4 detailed the measurements of FCE and its relevant traits in two groups. For RNA isolation, brain tissues were sampled immediately from sacrificed fish, frozen in liquid nitrogen and then stored at $-80{ }^{\circ} \mathrm{C}$ until further processing. All experimental procedures involved in fish in this study were based on institutional regulations and guideline for experimental animals of the Hubei Provincial Committee for Animal Welfare (Permit Number: 20130522-02).

Table 4. Descriptive statistics of feed conversion efficiency and relevant traits in crucian carp.

\begin{tabular}{ccc}
\hline Trait & Low Group & High Group \\
\hline $\mathrm{BW}_{\mathrm{I}}(\mathrm{g})$ & $0.69 \pm 0.12$ & $0.78 \pm 0.35$ \\
$\mathrm{BW}_{\mathrm{F}}(\mathrm{g})$ & $1.93 \pm 0.37$ & $4.25 \pm 1.87$ \\
$\mathrm{FI}(\mathrm{g})$ & $3.32 \pm 0.59$ & $4.63 \pm 2.20$ \\
FCE & $37.0 \pm 4.1 \%$ & $76.0 \pm 3.0 \%$ \\
\hline
\end{tabular}

$\mathrm{BW}_{\mathrm{I}}$ : initial body weight, FI: total feed intake, $\mathrm{BW}_{\mathrm{F}}$ : final body weight, FCE: feed conversion efficiency.

\subsection{RNA Extraction, Library Preparation and Transcriptome Sequencing}

Total RNA was isolated from the frozen brain samples using Trizol Reagent (Invitrogen, Carlsbad, CA, USA) according to the manufacturer's instructions. The RNA degradation and contamination was monitored on $1 \%$ agarose gels. RNA purity and concentration was measured by NanoPhotometer ${ }^{\circledR}$ spectrophotometer (IMPLEN, Westlake Village, CA, USA) and Qubit ${ }^{\circledR}$ 2.0 Flurometer (Life Technologies, Carlsbad, CA, USA). The RNA integrity number was assessed using the RNA Nano 6000 Assay Kit of the Agilent Bioanalyzer 2100 system (Agilent Technologies, Santa Clara, CA, USA), which ranged from 8.2 to 8.9 , suggesting that the samples were well preserved to meet the cDNA library construction requirements.

Sequencing libraries were generated using NEBNext ${ }^{\circledR} \mathrm{Ultra}^{\mathrm{TM}}$ RNA Library Prep Kit for Illumina ${ }^{\circledR}$ (NEB, Ipswich, MA, USA) according to manufacturer's recommendations. Oligo-dT beads (Qiagen, Dusseldorf, Germany) were used to separate poly (A) mRNA from the total RNA of each sample, and the fragmentation buffer was added to split all mRNA into short fragments. Then the first-strand cDNA was synthesized using the random hexamer-primed reverse transcription, and the second-strand cDNA was generated using RNase and DNA polymerase I. The cDNA fragments were washed by EB buffer for end reparation poly (A) after purification, and index codes were added to attribute sequences to each sample. Fragments with suitable size for sequencing were isolated from the agarose gels, and PCR amplification was used to enrich these fragments to construct the final cDNA libraries. Finally, the cDNA libraries were sequenced on an Illumina Hiseq 2000 platform and paired-end reads were generated.

\subsection{Transcriptome Assembly and Functional Annotation}

For ensuring high-quality data, raw data (raw reads) of fastq format were firstly processed through in-house Perl scripts, which eliminated all those reads with sequencing adapter and nucleotides in reads with quality value less than 20 in both end. In this step, good quality sequences of clean data (clean reads) were obtained by abandoning reads containing adapter, reads containing ploy- $\mathrm{N}$ and low-quality reads from raw data. At the same time, Q30, GC-content and sequence duplication level of the clean data were calculated. The clean data of this article are publicly available in the NCBI Sequence Reads Archive (SRA) with accession number PRJNA433432.

All clean reads of the six libraries were jointly assembled into contigs employed by Trinity software [56]. Since there is no reference genome of Carassius auratus, a k-mer value cutoff of 
25 was used after removing redundant nucleotide sequences by Tgicl (v2.1, http://sourceforge. net/projects/tgicl/files/tgicl\%20v2.1/). Then, unigenes were generated by connecting the contigs (longer than 200 bases) to obtain sequences that could not be extended on either end, and maximum length non-redundant unigenes were acquired by further splicing and assembling using TGICL clustering software (J. Craig Venter Institute, Rockville, MD, USA). Finally, unigenes were aligned against the $\mathrm{Nr}$ (NCBI non-redundant protein sequences), Swissprot (A manually annotated and reviewed protein sequence database), COG (Clusters of Orthologous Groups of proteins), and KEGG (Kyoto Encyclopedia of Genes and Genomes) of protein databases using BlastX with an $E$-value $<10^{-5}$. GO (Gene Ontology) annotation of these unigenes was performed using Blast2GO (https: / / www.blast2go.com/) based on the results of the NCBI Nr database annotation. Blastn was used to align these unigenes with the $\mathrm{Nr}$ database to search for proteins with the highest sequence similarity to the given unigenes and annotate their protein functions at the same time.

\subsection{Analysis of Differentially Expressed Genes (DEGs)}

Gene expression levels were estimated by RSEM (RNA-Seq by Expectation Maximization) [57] software package for each sample. The mapped reads were normalized according to fragment per kilobase of exon model per million mapped reads (FPKM) for each unigene between the two groups (Low_vs_High). Differentially expressed genes (DEGs) between the two groups were identified by the DEGseq package (samples with three biological replicates) applying the MA-plot-based method with Random Sampling model (MARS) method. In this study, DEGs with significant expression abundance between the two groups were selected using the following filter criteria: $p$-value $<0.01$ and the absolute value of $\log 2$ Ratio $\geq 1$, meaning each DEG between two groups should be at least two-fold. In order to determine the potential functions and metabolic pathways of these DEGs, COG, GO and KEGG enrichments were further analyzed. COG annotation of the DEGs was performed using Blastall software. GO enrichment analysis ( $p$-value $\leq 0.05$ ) of the DEGs was implemented by the topGO R packages based Kolmogorov-Smirnov test. Based on the hyper-geometric distribution model, we used KOBAS software [58] to test the statistical enrichment of DEGs in KEGG pathways, and the enrichment p-values were adjusted using the Benjamin and Hochberg method.

\subsection{Validation of RNA-Seq Results by $q R T-P C R$}

To confirm our differential expression results of RNA-Seq, we conducted quantitative reverse transcription PCR (qRT-PCR) assays for nine randomly selected DEGs in the same RNA samples used for RNA-Seq. First-strand cDNA was reverse-transcribed from total RNA using Reverse Transcriptase M-MLV (TaKaRa, Tokyo, Japan) with oligo-dT primer following the manufacturer's instructions. The first-strand cDNA from each sample was diluted by 1:5 with sterile distilled water and used as template. Primers (Table S2) for qRT-PCR analyses of the nine genes were designed using Primer 5 Software, and qRT-PCR was performed on a StepOneTM Real-Time PCR System (Applied Biosystems, Foster City, CA, USA). The qRT-PCR reaction solution consisted of $6.5 \mu \mathrm{L}$ Power SYBR Green PCR Master Mix (Applied Biosystems, Foster City, CA, USA), $0.2 \mu \mathrm{M}$ of each forward and reverse primer, $1.2 \mu \mathrm{L}$ diluted cDNA and $4.5 \mu \mathrm{L}$ sterile distilled water. PCR program was $95^{\circ} \mathrm{C}$ for $10 \mathrm{~min}$, followed by 40 cycles of $95^{\circ} \mathrm{C}$ for $15 \mathrm{~s}, 60^{\circ} \mathrm{C}$ for $30 \mathrm{~s}, 72^{\circ} \mathrm{C}$ for $45 \mathrm{~s}$. Three parallel experiments were conducted in each run for each sample. The relative expression levels were normalized towards the internal control gene of $\beta$-actin. Optimized comparative $C t$ value $\left(2^{-\Delta \Delta C T}\right)$ method [59] was used here to estimate gene expression levels.

\section{Conclusions}

We have reported a cerebric transcriptome of crucian carp using six fish with extremely low and high FCE. A total of 544,612 unigenes with a mean size of 644.38 bp were obtained from two FCE groups, and 246 DEGs that may be involved in FCE were identified. Based on GO and KEGG annotations, 13 DEGs related to metabolism, signal transduction and growth were identified to be key candidate 
genes associated with FCE traits. Our results provide valuable information for elucidating molecular mechanisms of feed conversion efficiency in fish, and these novel findings would be useful for such future studies as association analysis and functional genomics verification of candidate genes related to FCE in crucian carp.

Supplementary Materials: Supplementary materials can be found at www.mdpi.com/1422-0067/19/3/858/s1.

Acknowledgments: This research was supported by the Special Fund for Strategic Pilot Technology of Chinese Academy of Sciences (XDA08010405), State Key Laboratory of Freshwater Ecology and Biotechnology (2016FBZ05). We thank Shouqi Xie, Zhan Yin and Junyan Jin for their assistance in fish feeding and phenotypes recording.

Author Contributions: Jingou Tong conceived and guided this research. Meixia Pang carried out the experiments, performed data analysis and wrote the manuscript. Weiwei Luo and Beide Fu performed bioinformatics analysis. Xiaomu Yu and Ying Zhou prepared fish samples and performed the experiments. All authors read and approved the final manuscript.

Conflicts of Interest: The authors declare no conflict of interest.

\section{References}

1. Merino, G.; Barange, M.; Blanchard, J.L.; Harle, J.; Holmes, R.; Allen, I.; Allison, E.H.; Badjeck, M.B.; Dulvy, N.K.; Holt, J.; et al. Can marine fisheries and aquaculture meet fish demand from a growing human population in a changing climate? Glob. Environ. Chang. 2012, 22, 795-806. [CrossRef]

2. Easterling, W.E. Climate change and the adequacy of food and timber in the 21st century. Proc. Natl. Acad. Sci. USA 2007, 104, 19679. [CrossRef] [PubMed]

3. Rice, J.C.; Garcia, S.M. Fisheries, food security, climate change, and biodiversity: Characteristics of the sector and perspectives on emerging issues. ICES J. Mar. Sci. 2011, 68, 1343-1353. [CrossRef]

4. Alexandratos, N. How to Feed the World in 2050. Available online: http:/ / www.indiaenvironmentportal. org.in/files/How_to_Feed_the_World_in_2050.pdf. (accessed on 1 Octobor 2009).

5. Wringe, B.F.; Devlin, R.H.; Ferguson, M.M.; Moghadam, H.K.; Sakhrani, D.; Danzmann, R.G. Growth-related quantitative trait loci in domestic and wild rainbow trout (Oncorhynchus mykiss). BMC Genet. 2010, 11, 63. [CrossRef] [PubMed]

6. Laghari, M.Y.; Zhang, Y.; Lasgari, P.; Zhang, X.; Xu, P.; Xin, B.; Sun, X. Quantitative trait loci (QTL) associated with growth rate trait in common carp (Cyprinus carpio). Aquac. Int. 2013, 21, 1373-1379. [CrossRef]

7. Gjedrem, T.; Baranski, M. Selective Breeding in Aquaculture: An Introduction. Rev. Methods Technol. Fish Biol. Fish. 2009, 10, 570-572.

8. Sherman, E.L.; Nkrumah, J.D.; Li, C.; Bartusiak, R.; Murdoch, B.; Moore, S.S. Fine mapping quantitative trait loci for feed intake and feed efficiency in beef cattle. J. Anim. Sci. 2009, 87, 37-45. [CrossRef] [PubMed]

9. Barendse, W.; Reverter, A.; Bunch, R.J.; Harrison, B.E.; Barris, W.; Thomas, M.B. A validated whole-genome association study of efficient food conversion in cattle. Genetics 2007, 176, 1893-1905. [CrossRef] [PubMed]

10. Do, D.N.; Strathe, A.B.; Ostersen, T.; Pant, S.D.; Kadarmideen, H.N. Genome-wide association and pathway analysis of feed efficiency in pigs reveal candidate genes and pathways for residual feed intake. Front. Genet. 2014, 5, 307. [CrossRef] [PubMed]

11. Nkrumah, J.D.; Sherman, E.L.; Li, C.; Marques, E.; Crews, D.H.J.; Bartusiak, R.; Murdoch, B.; Wang, Z.; Basarab, J.A.; Moore, S.S. Primary genome scan to identify putative quantitative trait loci for feedlot growth rate, feed intake, and feed efficiency of beef cattle. J. Anim. Sci. 2007, 85, 3170-3181. [CrossRef] [PubMed]

12. Mignon-Grasteau, S.; Rideau, N.; Gabriel, I.; Chantry-Darmon, C.; Boscher, M.; Sellier, N.; Chabault, M.; Bihan-Duval, E.L.; Narcy, A. Detection of QTL controlling feed efficiency and excretion in chickens fed a wheat-based diet. Genet. Sel. Evol. 2015, 47, 74. [CrossRef] [PubMed]

13. De Koning, D.J.; Windsor, D.; Hocking, P.M.; Burt, D.W.; Law, A.; Haley, C.S.; Morris, A.; Vincent, J.; Griffin, H. Quantitative trait locus detection in commercial broiler lines using candidate regions. J. Anim. Sci. 2003, 81, 1158-1165. [CrossRef] [PubMed]

14. De Koning, D.J.; Haley, C.S.; Windsor, D.; Hocking, P.M.; Griffin, H.; Morris, A.; Vincent, J.; Burt, D.W. Segregation of QTL for production traits in commercial meat-type chickens. Genet. Res. 2004, 83, 211-220. [CrossRef] [PubMed] 
15. Wolc, A.; Arango, J.; Jankowski, T.; Settar, P.; Fulton, J.E.; O'Sullivan, N.P.; Fernando, R.; Garrick, D.J.; Dekker, J.C. Pedigree and genomic analyses of feed consumption and residual feed intake in laying hens. Poult. Sci. 2013, 92, 2270-2275. [CrossRef] [PubMed]

16. Do, D.N.; Ostersen, T.; Strathe, A.B.; Mark, T.; Jensen, J.; Kadarmideen, H.N. Genome-wide association and systems genetic analyses of residual feed intake, daily feed consumption, backfat and weight gain in pigs. BMC Genet. 2014, 15, 27. [CrossRef] [PubMed]

17. Gao, X.; Peng, L.; Ruan, X.; Chen, X.; Ji, H.; Ma, J.; Ni, H.; Jiang, S.; Guo, D. Transcriptome profile analysis reveals cardiotoxicity of maduramicin in primary chicken myocardial cells. Arch. Toxicol. 2017. [CrossRef] [PubMed]

18. Kang, X.; Liu, G.; Liu, Y.; Xu, Q.; Zhang, M.; Fang, M. Transcriptome profile at different physiological stages reveals potential mode for curly fleece in Chinese tan sheep. PLoS ONE 2013, 8, e71763. [CrossRef] [PubMed]

19. Wei, J.; Liu, B.; Fan, S.; Li, H.; Chen, M.; Zhang, B.; Su, J.; Meng, Z.; Yu, D. Differentially expressed immune-related genes in hemocytes of the pearl oyster Pinctada fucata against allograft identified by transcriptome analysis. Fish Shellfish Immunol. 2017, 62, 247-256. [CrossRef] [PubMed]

20. Luo, W.; Cao, X.; Xu, X.; Huang, S.; Liu, C.; Tomljanovic, T. Developmental transcriptome analysis and identification of genes involved in formation of intestinal air-breathing function of Dojo loach, Misgurnus anguillicaudatus. Sci. Rep. 2016, 6, 31845. [CrossRef] [PubMed]

21. Yi, G.; Yuan, J.; Bi, H.; Yan, W.; Yang, N.; Qu, L. In-Depth Duodenal Transcriptome Survey in Chickens with Divergent Feed Efficiency Using RNA-Seq. PLoS ONE 2015, 10, e0136765. [CrossRef] [PubMed]

22. Zhao, Y.; Hou, Y.; Liu, F.; Liu, A.; Jing, L.; Zhao, C.; Luan, Y.; Miao, Y.; Zhao, S.; Li, X. Transcriptome Analysis Reveals that Vitamin A Metabolism in the Liver Affects Feed Efficiency in Pigs. G3 Genes Genomes Genet. 2016, 6, 3615-3624. [CrossRef] [PubMed]

23. Paradis, F.; Yue, S.; Grant, J.R.; Stothard, P.; Basarab, J.A.; Fitzsimmons, C. Transcriptomic analysis by RNA sequencing reveals that hepatic interferon-induced genes may be associated with feed efficiency in beef heifers. J. Anim. Sci. 2015, 93, 3331-3341. [CrossRef] [PubMed]

24. Jégou, M.; Gondret, F.; Vincent, A.; Tréfeu, C.; Gilbert, H.; Louveau, I. Whole Blood Transcriptomics Is Relevant to Identify Molecular Changes in Response to Genetic Selection for Feed Efficiency and Nutritional Status in the Pig. PLoS ONE 2016, 11, e0146550. [CrossRef] [PubMed]

25. Gondret, F.; Vincent, A.; Houée-Bigot, M.; Siegel, A.; Lagarrigue, S.; Causeur, D.; Gilbert, H. A transcriptome multi-tissue analysis identifies biological pathways and genes associated with variations in feed efficiency of growing pigs. BMC Genom. 2017, 18, 244. [CrossRef] [PubMed]

26. Lu, C.; Laghari, M.Y.; Zheng, X.; Cao, D.; Zhang, X.; Kuang, Y.; Li, C.; Cheng, L.; Mahboob, S.; Al-Ghanim, K.A.; et al. Mapping quantitative trait loci and identifying candidate genes affecting feed conversion ratio based onto two linkage maps in common carp (Cyprinus carpio L.). Aquaculture 2017, 468, 585-596. [CrossRef]

27. Laghari, M.Y.; Lashari, P.; Zhang, Y.; Sun, X. Identification of Quantitative Trait Loci (QTLs) in Aquaculture Species. Rev. Fish. Sci. Aquac. 2014, 22, 221-238. [CrossRef]

28. Rhee, J.S.; Jeong, C.B.; Kim, I.C.; Lee, Y.S.; Lee, C.; Lee, J.S. Immune gene discovery in the crucian carp Carassius auratus. Fish Shellfish Immunol. 2013, 36, 240-251. [CrossRef] [PubMed]

29. Lü, Y.P.; Wang, X.F.; Zhang, X.P. Experiment on using the extract of perilla seed as feed additives for Allogynogenetic crucian carp. China Feed 2007, 8, 32-33.

30. Luo, W.; Wang, G.; Gong, W.; Xie, J.; Yu, D.; Li, Z. Effects of bioflocs technology (BFT) on growth and water quality of crucian carp (Carassius auratus var. pengze). J. South. Agric. 2014, 45, 318-322.

31. Pang, M.; Fu, B.; Yu, X.; Liu, H.; Wang, X.; Yin, Z.; Xie, S.; Tong, J. Quantitative trait loci mapping for feed conversion efficiency in crucian carp (Carassius auratus). Sci. Rep. 2017, 7, 16971. [CrossRef] [PubMed]

32. Liao, X.; Cheng, L.; Xu, P.; Lu, G.; Wachholtz, M.; Sun, X.; Chen, S. Transcriptome analysis of crucian carp (Carassius auratus), an important aquaculture and hypoxia-tolerant species. PLoS ONE 2013, 8, e62308. [CrossRef] [PubMed]

33. Li, C.Y.; Li, J.T.; Kuang, Y.Y.; Xu, R.; Zhao, Z.X.; Hou, G.Y.; Liang, H.W.; Sun, X.W. The transcriptomes of the crucian carp complex (Carassius auratus) provide insights into the distinction between unisexual triploids and sexual diploids. Int. J. Mol. Sci. 2014, 15, 9386-9406. [CrossRef] [PubMed]

34. Deng, Y.Y.; Li, J.Q.; Wu, S.F.; Zhu, Y.P.; Chen, Y.W.; He, F.C. Integrated nr Database in Protein Annotation System and Its Localization. Comput. Eng. 2006, 32, 71-74. 
35. Apweiler, R.; Bairoch, A.; Wu, C.H.; Barker, W.C.; Boeckmann, B.; Ferro, S.; Gasteiger, E.; Huang, H.; Lopez, R.; Magrane, M.; et al. UniProt: The Universal Protein knowledgebase. Nucleic Acids Res. 2004, 32, D115-D119. [CrossRef] [PubMed]

36. Tatusov, R.L.; Galperin, M.Y.; Natale, D.A.; Koonin, E.V. The COG database: A tool for genome scale analysis of protein functions and evolution. Nucleic Acids Res. 2000, 28, 33-36. [CrossRef] [PubMed]

37. Kanehisa, M.; Goto, S.; Kawashima, S.; Hattori, M. The KEGG resource for deciphering the genome. Nucleic Acids Res. 2004, 32, D277-D280. [CrossRef] [PubMed]

38. Niemann, H.; Kuhla, B.; Flachowsky, G. Perspectives for feed-efficient animal production. J. Anim. Sci. 2011, 89, 4344-4363. [CrossRef] [PubMed]

39. Doupé, R.G.; Lymbery, A.J. Toward the Genetic Improvement of Feed Conversion Efficiency in Fish. J. World Aquac. Soc. 2003, 34, 245-254. [CrossRef]

40. Dickerson, G.E. Animal size and efficiency: Basic concepts. Anim. Prod. 1978, 27, 367-379. [CrossRef]

41. Kushwaha, R.; Singh, A.K.; Kumar, M. Residual feed intake-An emerging system for selection of efficient animals: A review. Agric. Rev. 2016, 37, 66-71. [CrossRef]

42. Ogata, H.Y.; Oku, H.; Murai, T. Growth, feed efficiency and feed intake of offspring from selected and wild Japanese flounder (Paralichthys olivaceus). Aquaculture 2002, 211, 183-193. [CrossRef]

43. Imai, S.; Kai, M.; Yasuda, S.; Kanoh, H.; Sakane, F. Identification and characterization of a novel human type II diacylglycerol kinase, DGK kappa. J. Biol. Chem. 2005, 280, 39870-39881. [CrossRef] [PubMed]

44. Thameem, F.; Yang, X.; Permana, P.A.; Wolford, J.K.; Bogardus, C.; Prochazka, M. Evaluation of the microsomal glutathione S-transferase 3 (MGST3) locus on 1q23 as a Type 2 diabetes susceptibility gene in Pima Indians. Hum. Genet. 2003, 113, 353-358. [CrossRef] [PubMed]

45. Shimma, Y.; Nishikawa, A.; bin Kassim, B.; Eto, A.; Jigami, Y. A defect in GTP synthesis affects mannose outer chain elongation in Saccharomyces cerevisiae. Mol. Gen. Genet. 1997, 256, 469-480. [PubMed]

46. Weber, K.L.; Rincon, G.; Eenennaam, A.V. Genome-Wide Association Study and Differential Expression Analysis of Feed Efficiency using HD SNP Genotyping and Multiple Tissue RNAseq. In Proceedings of the International Plant and Animal Genome Conference XXII, San Diego, CA, USA, 10-15 January 2014.

47. Serão, N.V.L.; Gonzálezpeña-Peña, D.; Beever, J.E.; Faulkner, D.B.; Southey, B.R.; Rodriguez-Zas, S.L. Single nucleotide polymorphisms and haplotypes associated with feed efficiency in beef cattle. BMC Genet. 2013, 14, 94. [CrossRef] [PubMed]

48. Rasal, K.D.; Shah, T.M.; Vaidya, M.; Jakhesara, S.J.; Joshi, C.G. Analysis of consequences of non-synonymous $\mathrm{SNP}$ in feed conversion ratio associated TGF- $\beta$ receptor type 3 gene in chicken. Meta Gene 2015, 4, 107-117. [CrossRef] [PubMed]

49. Oksbjerg, N.; Gondret, F.; Vestergaard, M. Basic principles of muscle development and growth in meat-producing mammals as affected by the insulin-like growth factor (IGF) system. Domest. Anim. Endocrinol. 2004, 27, 219-240. [CrossRef] [PubMed]

50. Kuemmerle, J.F. Insulin-like growth factors in the gastrointestinal tract and liver. Endocrinol. Metab. Clin. N. Am. 2012, 41, 409-423. [CrossRef] [PubMed]

51. Zhang, Y.; Huang, X.L.; Cong, L.; Peng, Z.J.; Zhang, D.X. The study on the relations of chicken IGF-1 gene and feed conversion traits. Heilongjiang Anim. Sci. Vet. Med. 2013, 7, 37-39.

52. Kinoshita, S.; Siddique, B.S.; Ceyhun, S.B.; Asaduzzaman, M.; Asakawa, S.; Watabe, S. Species-specific expression variation of fish MYH14, an ancient vertebrate myosin heavy chain gene orthologue. Fish. Sci. 2011, 77, 847-853. [CrossRef]

53. Cui, X.; Hou, Y.; Yang, S.; Xie, Y.; Zhang, S.; Zhang, Y.; Zhang, Q.; Lu, X.; Liu, G.E.; Sun, D. Transcriptional profiling of mammary gland in Holstein cows with extremely different milk protein and fat percentage using RNA sequencing. BMC Genom. 2014, 15, 226. [CrossRef] [PubMed]

54. Coble, D.J.; Fleming, D.; Persia, M.E.; Ashwell, C.M.; Rothschild, M.F.; Schmidt, C.J. RNA-seq analysis of broiler liver transcriptome reveals novel responses to high ambient temperature. BMC Genom. 2014, 15, 1084. [CrossRef] [PubMed]

55. Zhang, Y.; Li, Y.; Liang, X.; Cao, X.; Huang, L.; Yan, J.; Wei, Y.; Gao, J. Hepatic transcriptome analysis and identification of differentially expressed genes response to dietary oxidized fish oil in loach Misgurnus anguillicaudatus. PLoS ONE 2017, 12, e0172386. [CrossRef] [PubMed] 
56. Grabherr, M.G.; Haas, B.J.; Yassour, M.; Levin, J.Z.; Thompson, D.A.; Amit, I.; Adiconis, X.; Fan, L.; Raychowdhury, R.; Zeng, Q.; et al. Trinity: Reconstructing a full-length transcriptome without a genome from RNA-Seq data. Nat. Biotechnol. 2011, 29, 644-652. [CrossRef] [PubMed]

57. Li, B.; Dewey, C.N. RSEM: Accurate transcript quantification from RNA-Seq data with or without a reference genome. BMC Bioinform. 2011, 12, 323. [CrossRef] [PubMed]

58. Mao, X.; Cai, T.; Olyarchuk, J.G.; Wei, L. Automated genome annotation and pathway identification using the KEGG Orthology (KO) as a controlled vocabulary. Bioinformatics 2005, 21, 3787-3793. [CrossRef] [PubMed]

59. Livak, K.J.; Schmittgen, T.D. Analysis of Relative Gene Expression Data Using Real-Time Quantitative PCR and the $2^{-\triangle \triangle C T}$ Method. Methods 2012, 25, 402-408. [CrossRef] [PubMed]

(c)

(C) 2018 by the authors. Licensee MDPI, Basel, Switzerland. This article is an open access article distributed under the terms and conditions of the Creative Commons Attribution (CC BY) license (http:/ / creativecommons.org/licenses/by/4.0/). 